ARTICLE

\title{
A palladium-catalysed multicomponent coupling approach to conjugated poly(1,3-dipoles) and polyheterocycles
}

David C. Leitch ${ }^{1, \star}$, Laure V. Kayser ${ }^{1, \star}$, Zhi-Yong Han ${ }^{1, \star}$, Ali R. Siamaki ${ }^{1}$, Evan N. Keyzer ${ }^{1}$, Ashley Gefen ${ }^{1} \&$ Bruce A. Arndtsen ${ }^{1}$

Conjugated polymers have emerged over the past several decades as key components for a range of applications, including semiconductors, molecular wires, sensors, light switchable transistors and OLEDs. Nevertheless, the construction of many such polymers, especially highly substituted variants, typically involves a multistep synthesis. This can limit the ability to both access and tune polymer structures for desired properties. Here we show an alternative approach to synthesize conjugated materials: a metal-catalysed multicomponent polymerization. This reaction assembles multiple monomer units into a new polymer containing reactive 1,3-dipoles, which can be modified using cycloaddition reactions. In addition to the synthetic ease of this approach, its modularity allows easy adaptation to incorporate a range of desired substituents, all via one-pot reactions.

\footnotetext{
${ }^{1}$ Department of Chemistry, McGill University, 801 Sherbrooke Street West, Montreal, Quebec, Canada H3A OK8. * These authors contributed equally to this work. Correspondence and requests for materials should be addressed to B.A.A. (email: bruce.arndtsen@mcgill.ca).
} 
A central goal in polymer synthesis is to directly convert simple chemical building blocks into useful materials. While a wide variety of interesting and potentially important structurally complex polymers have been discovered through recent research efforts (for example, biopolymers, advanced polymer networks, responsive materials and so on), their synthesis via traditional methods can be sufficiently involved to limit their accessibility, especially with the efficiency often demanded in polymer synthesis. One area where structure complexity has proven particularly powerful is in the field of $\pi$-conjugated polymers. The development of poly(heterocycles) (polypyrroles ${ }^{1}$, polythiophenes ${ }^{2,3}$ and others ${ }^{4-6}$ ) and their copolymers has sparked a renaissance in how scientists consider constructing a host of organic electronics, such as semiconductors, photovoltaic devices, or sensors ${ }^{7-10}$. A useful feature of conjugated polymers is their tunability. The modulation of substituents, conjugated heteroatoms or alternating backbone units can allow the construction of conjugated polymers with tailored electronic and other physical features. A number of powerful approaches have been developed to access conjugated polymers, including the now commonplace use of cross-coupling methodologies ${ }^{11,12}$. While very effective, these often achieve complexity from the monomers themselves, which can in some instances require a multistep synthesis, followed by halogenation and metallation, and can make accessing varied polymer structures an iterative process. The latter have made the development of alternative methods to construct conjugated polymers an area of growing relevance ${ }^{13-15}$.

In principle, an attractive synthesis of complex conjugated polymers would be to consider their structure as arising directly from available monomers. A challenge is in how to accomplish this in an efficient fashion. One possibility is offered by multicomponent coupling reactions. Multicomponent reactions have been heavily exploited in organic synthesis to increase molecular complexity without the need for multistep synthetic sequences, with high efficiency and minimal waste ${ }^{16,17}$. When coupled with transition metal catalysis, these can provide methods to both activate and selectively couple several simple substrates directly into complex products ${ }^{18-20}$. Although metal catalysis is an established tool for activating typically unreactive components towards efficient polymerization (for example, polyolefin synthesis, ring-opening polymerization and so on), the use of metal catalysis to control the coupling of multiple different monomers into new, well-defined and more complex polymer structures is much less explored. Block terpolymer synthesis is well established ( $\mathbf{I}$; Fig. 1a), and a number of intriguing examples have recently emerged in the metalcatalysed assembly of alternating multicomponent polymers II (refs 21-27), including the synthesis of conjugated ${ }^{22,23}$ and high-molecular-weight materials ${ }^{27}$. However, a method to directly convert multiple simple monomers into an entirely new polymer structure such as III has to our knowledge not been reported. Considering the variety of monomers relevant for polymerization (for example, diamines, diacids, alkenes, alkynes and so on), this method could provide an efficient route to access a diverse variety of structurally complex polymers, yet do so through combinations of available substrates, with high efficiency, and with facile access to structural diversity.

A polymerization as in Fig. 1a requires a multicomponent reaction that is selective, high yielding, yet relies upon available monomers. A potential transformation that fulfils these features is the palladium-catalysed synthesis of heterocycles shown in Fig. 1b. We have recently reported a palladium-catalysed route to generate 1,3-dipoles 4 (Münchnones) from imines, acid chlorides and carbon monoxide $(\mathrm{CO})^{28,29}$. This reaction proceeds in high efficiency and is equally important with substrates that are all easily accessible for a polymerization: imines, acid chlorides and CO. 1,3-Dipoles, including di-Münchnones, have been used in condensation chemistry to synthesize cross-conjugated materials in low molecular weights (Fig. 1c; refs 30,31). A more attractive approach suggested by this palladium-catalysed synthesis would be to couple simple diimines, diacid chlorides and $\mathrm{CO}$ into a novel type of mesoionic, 1,3-dipole-containing conjugated polymer 4 . Münchnones are known to undergo a variety of 1,3-dipolar cycloaddition reactions with unsaturated substrates $(A \equiv B)$ to generate nitrogen-containing heterocycles ${ }^{32}$. As such, this platform would allow the assembly of various structurally distinct polymers from multiple combinations of available substrates.

We describe here our efforts towards the development of such a metal-catalysed multicomponent polymerization reaction. This has allowed the assembly $\pi$-conjugated poly(heterocycles) from multiple combinations of simple monomers: diimines, diacid chlorides, $\mathrm{CO}$, alkenes and/or alkynes. In addition to demonstrating the feasibility of this strategy, this reaction allows access to a new class of conjugated polymer in the form of a mesoionic poly(1,3-dipole). The polymers can be easily modified by cycloaddition, providing access to families of conjugated materials in one-pot, metal-catalysed reactions.
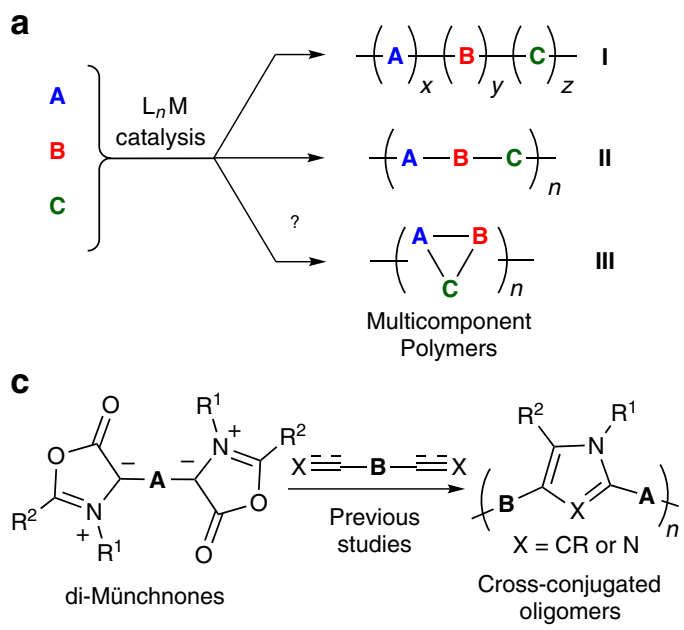

b
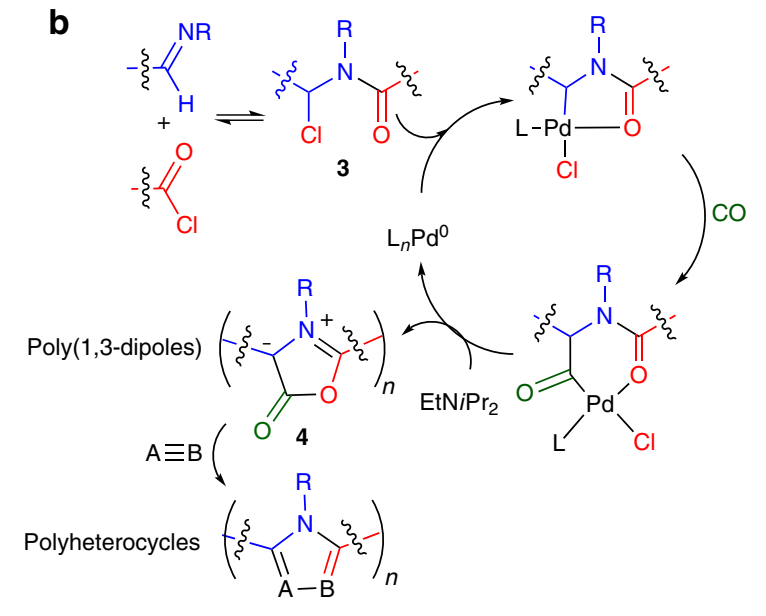

Figure 1 | Multicomponent approaches to complex polymer synthesis. (a) Metal-catalysed multicomponent coupling approaches to polymers. (b) Palladium-catalysed Münchnone formation. (c) Previous work involving di-Münchnones in oligomer synthesis. 


\section{Results}

Multicomponent synthesis of conjugated polypyrroles. As model monomers for the polymerization, we examined the palladium-catalysed coupling of terephthaloyl chloride 1a, diimine 2a based on dialkylfluorene and $\mathrm{CO}$ (Table 1). The efficiency of this polymerization was determined by reacting $\mathbf{4 a}$ with the commercial alkyne dimethylacetylene dicarboxylate to form the polypyrrole 5a. Using simple Pd(II) sources, with or without the addition of phosphines ligands, leads to no polymerization (entries 1-4), presumably owing to their slow reduction under the mild reaction conditions. Conversely, the common $\mathrm{Pd}(0)$ catalyst $\mathrm{Pd}_{2} \mathrm{dba}_{3} \bullet \mathrm{CHCl}_{3} \quad(\mathrm{dba}=$ dibenzylidene acetone) results in the rapid conversion of starting materials to form a poorly soluble, amorphous product (entry 7). Gel permeation chromotography (GPC) analysis shows that the tetrahydrofuran (THF) soluble fraction contains a polymer $\left(M_{\mathrm{n}}=7.8 \mathrm{kDa}\right)$ but with a broad polydispersity $(\mathrm{PDI}=3.4)$. The addition of $\mathrm{PPh}_{3}$ or $\mathrm{PCy}_{3}$ in an attempt to attenuate the reactivity of the palladium catalyst leads instead to complete inhibition of the reaction (entries 5, 8 and 9) while $\mathrm{P}(o \text {-tol })_{3}$ restores activity but yields a similarly poorly soluble product with a broad PDI (entry 10).

The low solubility and broad PDI in this product may be the alkene-based dba on the palladium precatalyst, which could react via cycloaddition with $\mathbf{4 a}$ and lead to crosslinking. To circumvent this reaction, $\mathrm{Pd}\left[\mathrm{P}(o-\text { tol })_{3}\right]_{2}$ was used as a commercially available source of $\operatorname{Pd}(0)$ with only weakly associated, and unreactive, ligands. This catalyst leads to the near-complete consumption of the reagents under mild conditions $\left(50^{\circ} \mathrm{C}, 4 \mathrm{~atm} \mathrm{CO}\right)$, and the generation of a polymer (5a) that is soluble in common solvents (entry 11 ). ${ }^{1} \mathrm{H}$ and ${ }^{13} \mathrm{C}$ nuclear magnetic resonance (NMR) and infrared (IR) analysis show the conversion of the monomers into the polypyrrole $\mathbf{5 a}$, which has identical spectral features to independently prepared model compounds (Supplementary Figs 5 and 16). GPC analysis shows 5a to have a well-defined monomodal molecular weight distribution $(\mathrm{PDI}=1.6)$. The catalytic activity of $\mathrm{Pd}\left[\mathrm{P}(o \text {-tol })_{3}\right]_{2}$ can be enhanced by the addition of $\mathrm{CuPF}_{6}$, which presumably acts as a phosphine scavenger to generate a mono-ligated palladium catalyst (entry 12). Alternatively, simply using high CO pressure leads to a rapid and near-quantitative polymerization, forming polypyrrole 5a as the only observable product (entry 13). Molecular weights as high as $22.7 \mathrm{kDa}$ can be obtained by increasing the concentration and reaction time (entry 14).

Synthesis of poly(1,3-dipoles). The reaction in Table 1 provides a new approach to synthesize pyrrole-based conjugated polymers from combinations of substrates that are either available or monomers themselves in other polymerizations (terephthaloyl chloride, CO, dialdehydes and alkynes). This platform can also be used to access new classes of conjugated materials. For example,

Table 1 | A multicomponent synthesis of conjugated polypyrroles`.

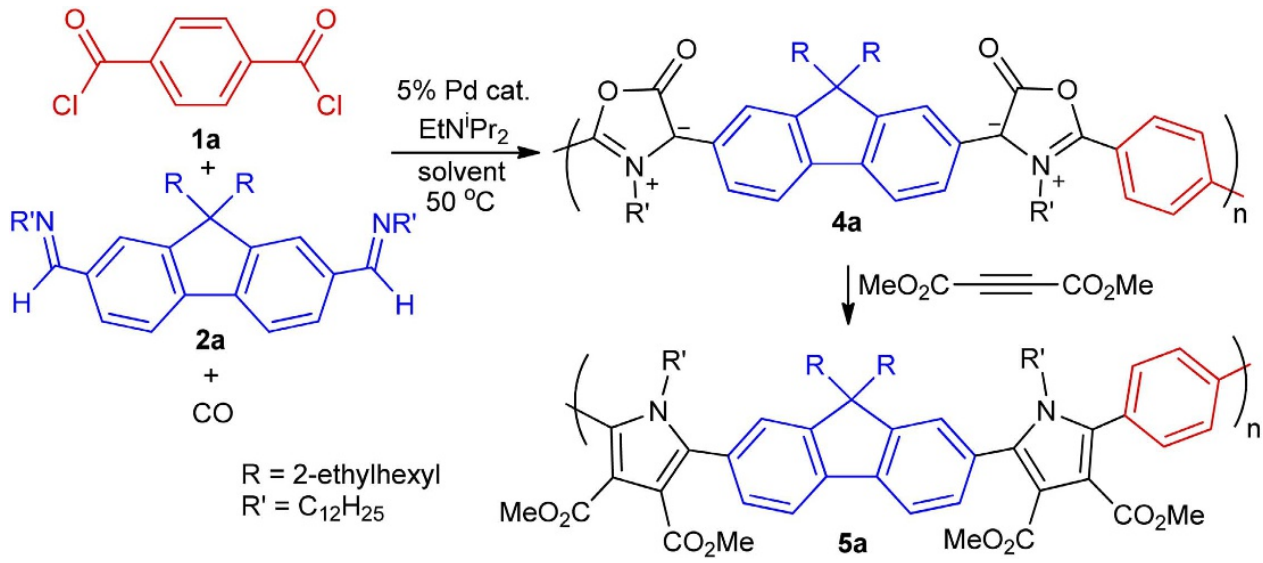

\begin{tabular}{|c|c|c|c|c|c|}
\hline Entry & Catalyst & Yield & $M_{\mathrm{n}}(\mathrm{kDa})$ & $M_{\mathrm{w}}(\mathrm{kDa})$ & PDI \\
\hline 1 & $\mathrm{PdCl}_{2}(\mathrm{PhCN})_{2}$ & NR & - & - & - \\
\hline 2 & $\mathrm{PdCl}_{2}\left(\mathrm{PPh}_{3}\right)_{2}$ & NR & - & - & - \\
\hline 3 & $\mathrm{PdCl}_{2}(\mathrm{PhCN})_{2} / \mathrm{P}(\text { o-tol })_{3}$ & NR & - & - & - \\
\hline 4 & $\operatorname{Pd}(O A c)_{2}$ & NR & - & - & - \\
\hline 5 & $\mathrm{Pd}\left(\mathrm{PPh}_{3}\right)_{4}$ & NR & - & - & - \\
\hline 6 & $\mathrm{Pd}\left[\mathrm{P}(t-\mathrm{Bu})_{3}\right]_{2}$ & 50 & 2.0 & 3.4 & 1.4 \\
\hline 7 & $\mathrm{Pd}_{2} \mathrm{dba}_{3} \cdot \mathrm{CHCl}_{3}$ & 70 & $7.8^{\ddagger}$ & 26.5 & 3.4 \\
\hline 8 & $\mathrm{Pd}_{2} \mathrm{dba}_{3} / \mathrm{PPh}_{3}$ & NR & - & - & - \\
\hline 9 & $\mathrm{Pd}_{2} \mathrm{dba}_{3} / \mathrm{PCy}_{3}$ & NR & - & - & - \\
\hline 10 & $\mathrm{Pd}_{2} \mathrm{dba}_{3} / \mathrm{P}(\mathrm{o} \text {-tol })_{3}$ & 75 & $7.4^{\ddagger}$ & 28.1 & 3.8 \\
\hline 11 & $\mathrm{Pd}\left[\mathrm{P}(\mathrm{o}-\mathrm{tol})_{3}\right]_{2}$ & 60 & 5.5 & 8.8 & 1.6 \\
\hline 12 & $\mathrm{Pd}\left[\mathrm{P}(\mathrm{o}-\mathrm{tol})_{3}\right]_{2} \S$ & 69 & 7.0 & 10.5 & 1.5 \\
\hline 13 & $\operatorname{Pd}\left[\mathrm{P}(o-\text { tol })_{3}\right]_{2} \|$ & 85 & 12.7 & 25.2 & 1.9 \\
\hline 14 & $\operatorname{Pd}\left[\mathrm{P}(0-\text { tol })_{3}\right]_{2}$ & 73 & 22.7 & 56.6 & 2.5 \\
\hline
\end{tabular}

1a $(0.10 \mathrm{mmol}), \mathbf{2 a}(0.10 \mathrm{mmol}), \mathrm{EtN}^{\prime} \mathrm{Pr}_{2}(0.40 \mathrm{mmol}), 4 \mathrm{~atm} \mathrm{CO}, 5 \% \mathrm{Pd} /$ pyrrole, THF, $50{ }^{\circ} \mathrm{C}, 24 \mathrm{~h}$; then $\mathrm{PhCOCl}(0.10 \mathrm{mmol}), 4 \mathrm{ml} \mathrm{CH} \mathrm{Cl}_{2}$, alkyne $(0.40 \mathrm{mmol})$, room temperature, $18 \mathrm{~h}$ $\mathbf{5 a}$, isolated yield, $\mathrm{NR}=$ no reaction. 
the first step in the transformation in Table 1 also generates the 1,3-dipole-containing polymer 4a. 1,3-Dipoles such as Münchnones are typically considered reactive intermediates and used in situ in synthesis. However, while performing the palladiumcatalysed coupling in the absence of alkyne, we noted the precipitation of a dark solid $\mathbf{4 a}$ that can be easily isolated by washing with acetonitrile. This polymer is surprisingly stable $\left(<5 \%\right.$ mass loss at up to $180^{\circ} \mathrm{C}$ under nitrogen), and can be stored at low temperature in the absence of air and moisture, although it does hydrolyse in the presence of water. In order to fully characterize the moderately soluble $\mathbf{4 a}$ by NMR analysis, it was prepared in moderate molecular weight with an imine endcapping agent $\left(4 \mathbf{a}^{\prime}, M_{\mathrm{n}}=6.7 \mathrm{kDa}\right.$; Supplementary Methods). Spectral analysis show all the signals for a Münchnone, including characteristic carbonyl resonances in the infrared $\left(1,710 \mathrm{~cm}^{-1}\right)$ spectra, in the ${ }^{13} \mathrm{C}$ NMR $(\delta 160.6)$ and others, all of which correlate with the model di-Münchnone $\mathbf{4} \mathbf{a}^{\prime \prime}$ prepared from diimine 2a, toluoyl chloride and CO. Therefore, 4 a represents an unusual new class of mesoionic polymer, poly(1,3-dipoles).

Donor/acceptor-conjugated polymers have become an important thrust in the recent design of polymer-based photovoltaic materials ${ }^{7,8,33}$, although these do not typically incorporate formal charges into the backbone. Likely as a result of this charge separation, poly-Münchnone $\mathbf{4 a}$ is a dark purple solid, characteristic of low-bandgap materials. Ultraviolet/visible analysis shows intense (molar absorptivity up to $5.0 \times 10^{4} 1 \mathrm{~mol}^{-1} \mathrm{~cm}^{-1}$ ) and broad absorptions in most of the visible region (Fig. 2a). These are significantly red-shifted relative to the model bis-Münchnone, and indicate that $\mathbf{4 a}$ is highly conjugated. While the precise nature of this extended conjugation is still under investigation, the persistent charge-separated character of the mesoionic moieties creates a donor/acceptor motif on a single heterocycle, and may also
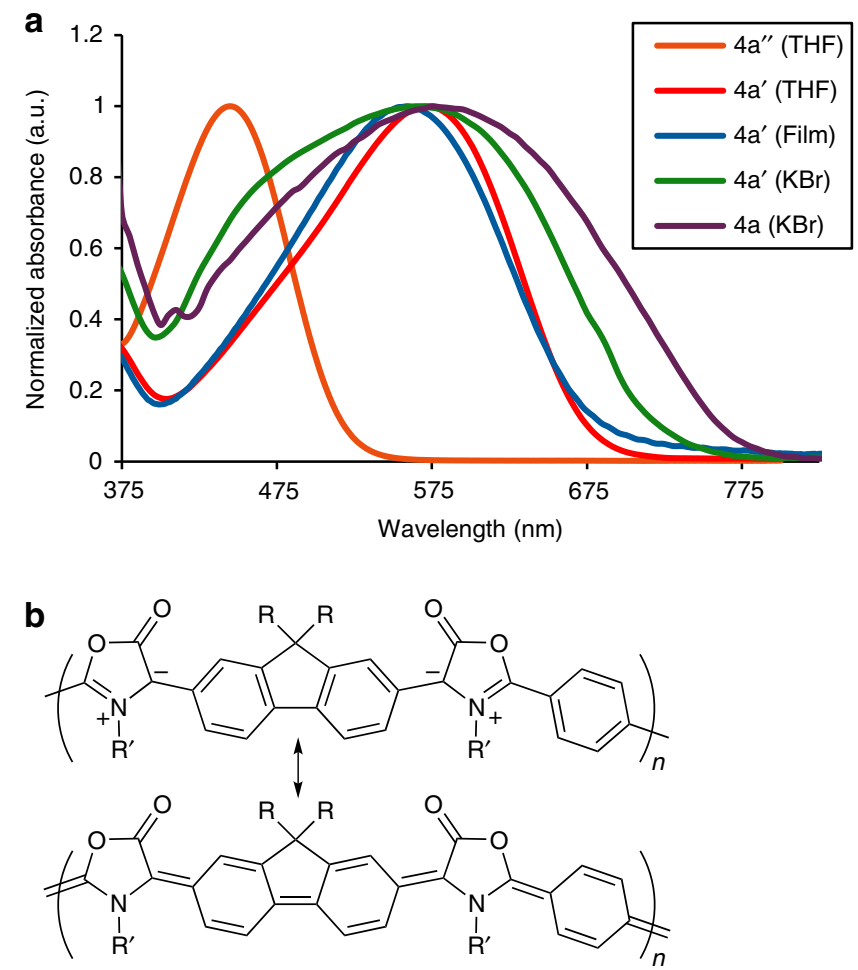

Figure 2 | Ultraviolet/visible spectra and conjugation in poly-

Münchnones. (a) Ultraviolet/visible spectra of $\mathbf{4 a}(22.7 \mathrm{kDa}), \mathbf{4 a} \mathbf{a}^{\prime}(6.7 \mathrm{kDa})$ and model dimer $4 a^{\prime \prime}(n=1)$. (b) Potential resonance structures of $4 \mathbf{a}$ leading to planarization. provide a novel route to planarization as a mechanism to partially eliminate charge (for example, Fig. 2b). Estimation of the optical bandgap by absorbance onset gives values of $1.74 \mathrm{eV}$ for $\mathbf{4} \mathbf{a}^{\prime}$ $(1.59 \mathrm{eV}$ for the high-molecular-weight $\mathbf{4 a})$, and cyclic voltammetry shows a reversible reduction and an electrochemical bandgap of $1.84 \mathrm{eV}$. As such, these are a new class of low-bandgap-conjugated materials.

In addition to their unusual electronic properties, the synthesis of 4 from diimines and diacid chlorides makes it straightforward to attenuate their structure and form a range of mesoionic polymers. Examples of the structural diversity available are shown in Fig. 3. Notably, each of the bis(acid chloride) monomers are either commercially available or easily prepared from the diacid compounds. For example, 2,5-thiophene dicarbonyl dichloride (precursor to 4c) can be synthesized in one step from adipic acid, a commodity chemical used in the production of nylon and other polyamides, whereas 2,5-furan dicarboxylic acid is derived from carbohydrates and identified by the US Department of Energy as one of the top 10 bio-based renewable chemicals ${ }^{34}$. The diimines used can be similarly altered to incorporate carbazole (4e), a common unit in conjugated polymer production ${ }^{8}$. In all cases, the catalytic coupling is clean and molecular weights are limited only by the solubility of the poly(1,3-dipole).

The structural manipulations translate into the properties of these polymers (Fig. 4a,b). For example, the disubstituted carbazole-containing polymer $4 \mathbf{e}$ displays visible absorbances that are blue-shifted $\left(\lambda_{\max }\right.$ of $\left.539 \mathrm{~nm}\right)$ relative to $4 \mathbf{a}\left(\lambda_{\max }\right.$ of $570 \mathrm{~nm}$; Fig. 4a). Alternatively, the thiophene-containing material 4b is significantly red-shifted relative to these other polymers (absorbance onset $\sim 768 \mathrm{~nm}$ ), corresponding to an optical bandgap of $1.58 \mathrm{eV}$. The latter is comparable to materials currently of interest as light harvesting materials in bulk heterojunction solar cells ${ }^{7,8}$. As such, this provides a method to both construct low-bandgap-conjugated polymers and manipulate or tune their electronic properties by choice of the constituent components.
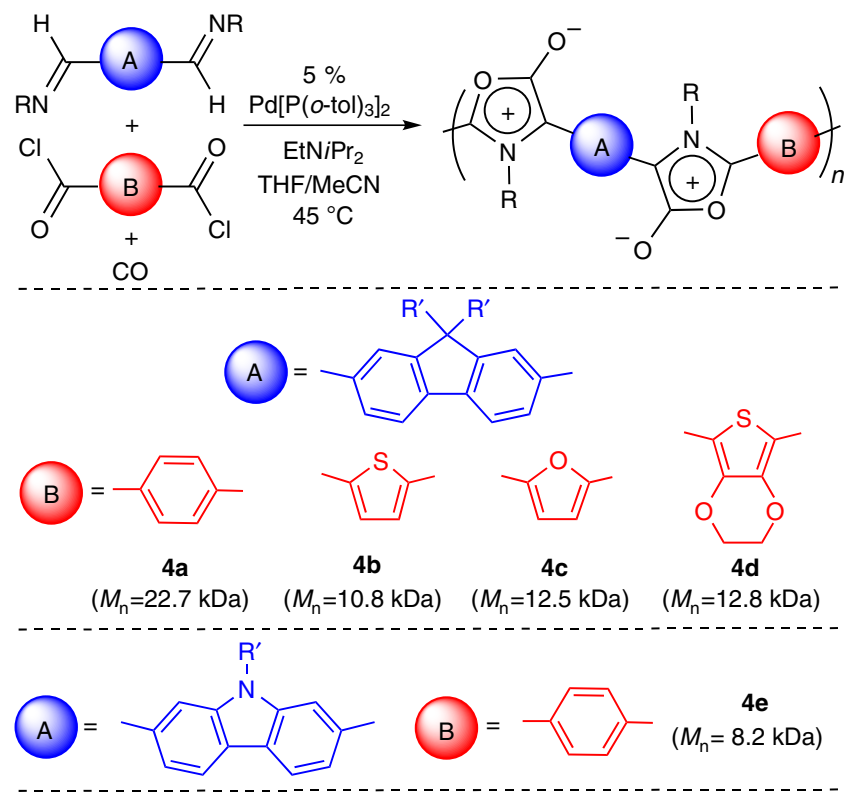

Figure 3 | Diversity of Münchnone-containing polymers. Owing to the moisture sensitivity of $\mathbf{4}$, molecular weight determined by conversion to polypyrroles $\mathbf{5}$, as in Table 1. 

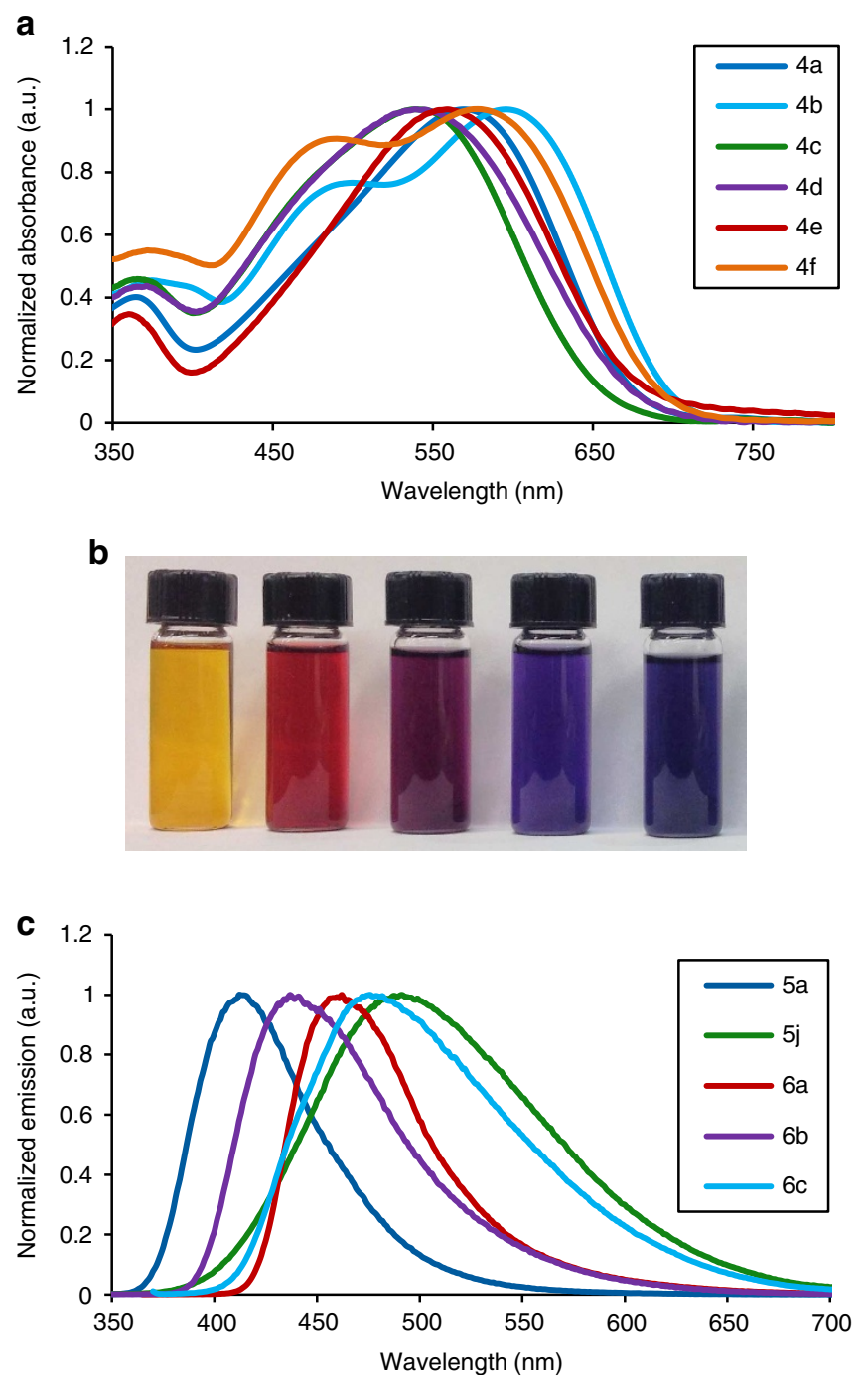

Figure 4 | Properties of polymers. Polymers were prepared with imine end-capping at 6-8 kDa to ensure full solubility for analyses (Supplementary Methods). (a) Ultraviolet/visible absorbance spectra of poly-Münchnones $\mathbf{4 a}-\mathbf{f}$ in THF. (b) Polymers $5 \mathbf{a}, \mathbf{4} \mathbf{f}^{\prime}, \mathbf{4} \mathbf{e}^{\prime}, \mathbf{4} \mathbf{a}^{\prime}$ and $\mathbf{4} \mathbf{c}^{\prime}$ in THF (from left to right). (c) Fluorescence spectra of select polymers 5-6 in THF.

Multicomponent synthesis of poly(heterocycles). These polyMünchnones 4 also offer access to another deeper level of molecular complexity via their backbone reactivity. This can provide, to our knowledge, a unique route to convert one conjugated organic polymer into other backbone-conjugated polymers ${ }^{35-37}$. For example, the addition of phenyl methylpropiolate to $\mathbf{4 a}$ results in the transformation of the purple, low-bandgap poly-Münchnone into a moderate bandgap, blue-emitting polypyrrole 5b (Fig. 5). ${ }^{1} \mathrm{H}$ NMR and infrared analysis suggest the complete disappearance of 1,3-dipole unit in this reaction, with no observable byproducts. In order to quantify the efficiency of cycloaddition, ${ }^{13} \mathrm{C}$-labelled polymer $4 \mathbf{a}$ was generated from isotopically enriched terephthaloyl chloride $4-\mathrm{C}_{6} \mathrm{H}_{4}\left({ }^{13} \mathrm{COCl}\right)_{2}$. NMR $\left({ }^{13} \mathrm{C}\right)$ analysis shows the quantitative reaction with alkyne to form polypyrrole (>95\%; see Supplementary Methods for details), and is consistent with the high cycloaddition reactivity of the 1,3-dipoles. A range of pyrrole-based polymers can be formed by this reaction. For example, changing the alkyne used can provide access to a wide variety of pyrrole-based polymers. Representative examples of these include the diester-containing polymer $\mathbf{5 a}$ or the diketonesubstituted $\mathbf{5 c}$. In addition to alkynes, electron-deficient alkenes are suitable dipolarophiles to form pyrroles. This can allow the facile formation of fused ring pyrrole-based polymer 6a (from cyclic alkene cycloaddition), the mono-substituted $\mathbf{6 b}$ (from chlorocyanoethylene) or the unsubstituted polypyrrole $\mathbf{6 c}$ with high yield. By using different diimines and diacid chlorides, various other polypyrroles can be obtained (for example, $\mathbf{5 d}-\mathbf{5} \mathbf{h}$ ). As such, this provides a platform to readily incorporate desired functionalities onto conjugated polymers, all of which emanate from a single polymer 4 . The reactivity of Münchnones is also not limited to pyrroles. The addition of $N$-tosyl imine forms imidazole-based-conjugated polymer 7 , and backbone conjugation in these polymers can be easily quenched by the addition of alcohols, leading to the generation of polyamides $\mathbf{8}$. Poly-Münchnones $\mathbf{4}$ can therefore be considered highly reactive and versatile conjugated materials, where a single polymer 4 can be transformed into entire families of new conjugated materials. In the case of phenyl methylpropiolate, this polymerization can be performed in a single step (Fig. 6), thereby allowing the orthogonal, four-component synthesis of a conjugated polymer.

This structural diversity can provide a further platform to modulate properties. For example, between polymers 4 and $\mathbf{8}$, optical absorbance and polymer bandgap can be tuned across the visible spectrum, and materials can be formed that fluoresce anywhere from blue to green to not at all (Fig. 4c and Table 2; Supplementary Tables 1 and 2 for the full list of properties). Similarly, electrochemical studies show that this cycloaddition (or lack thereof) can be used to tune HOMO energies by over $1 \mathrm{eV}$. While the primary thrust of these studies was not in product design, several of the polymers reported here display notable properties. Polypyrroles and their copolymers have attracted significant interest as electronic materials ${ }^{1,38}$. Three of the pyrrole-based polymers $(\mathbf{5 a}, \mathbf{6 a}$ and $\mathbf{6 b})$ have good photoluminescent quantum efficiency ( $>35 \%$ ) with emission maxima in the range of blue light $(413-459 \mathrm{~nm})$. Alternatively, the pyrrole-based imide-functionalized unit has been identified as a promising electron acceptor unit in conjugated polymers, and can be readily generated by this approach (6a; ref. 39), while alternating pyrrole-thiophene materials such as $\mathbf{6 d}$ represent new variants of materials found to be of use in field-effect transistors ${ }^{40}$. The range of properties observed is a direct result of their structural diversity, which varies from the backboneconjugated heterocycles, the spacer units, to the substituents. This level of structural attenuation would require an individual synthesis for each new monomer via typical methods. In this case, each polymer is generated in one pot, from a small pool of monomers, and with minimal waste (often only $\mathrm{HCl}$ and $\mathrm{CO}_{2}$ ).

Synthesis of polymers from vanillin. Finally, we have examined the potential of using other renewable materials as precursors to conjugated polymers. Lignin is a major component of lignocellulosic biomass and the world's largest renewable source of aromatic compounds, thereby making it a potentially attractive, bio-based feedstock for $\pi$-conjugated polymers ${ }^{41}$. Lignin depolymerization yields a variety of aromatic building blocks, including the dialdehyde 9 (a dimer of vanillin). As this multicomponent polymerization uses aldehydes and carboxylic acids as monomer feedstocks, 9 can be incorporated in this palladium-catalysed polymerization to generate the conjugated poly-Münchnone $4 \mathrm{ff}$ (Fig. 7). Ultraviolet/visible and electrochemical studies show that 4 ff is a moderately low-bandgap polymer $(1.9 \mathrm{eV})$. As above, the dipole in $\mathbf{4 f}$ can undergo cycloaddition reactions to generate the polypyrroles $5 \mathbf{i}$ and $\mathbf{5 j}$, each of which are blue-emitting materials. These polymers are 

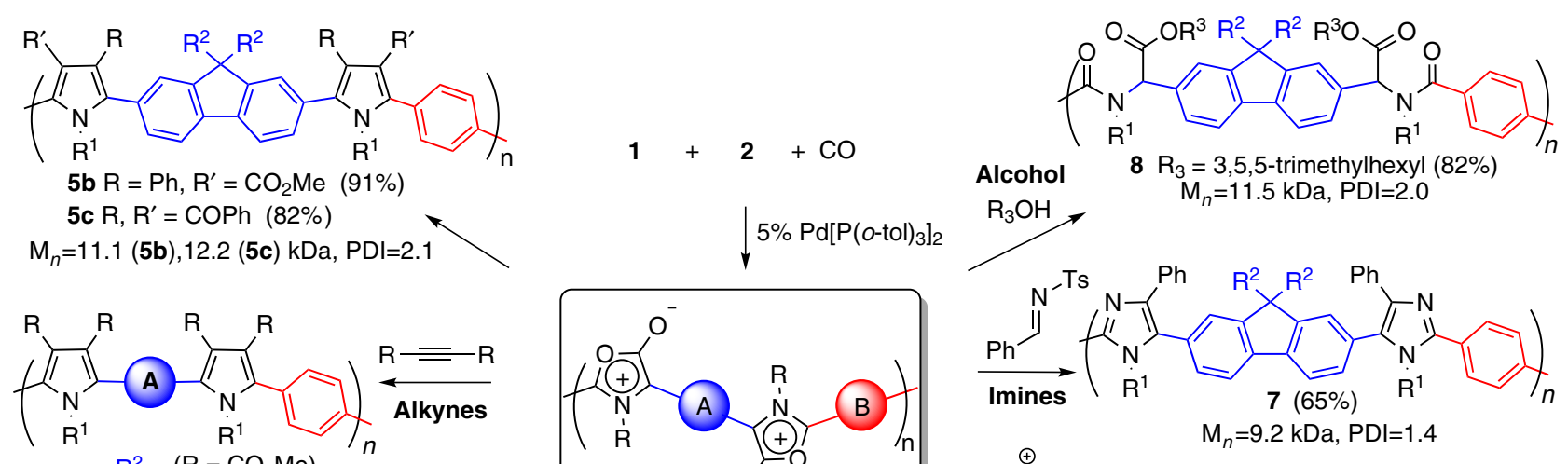

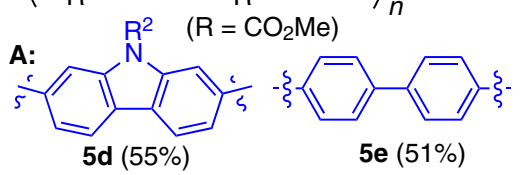
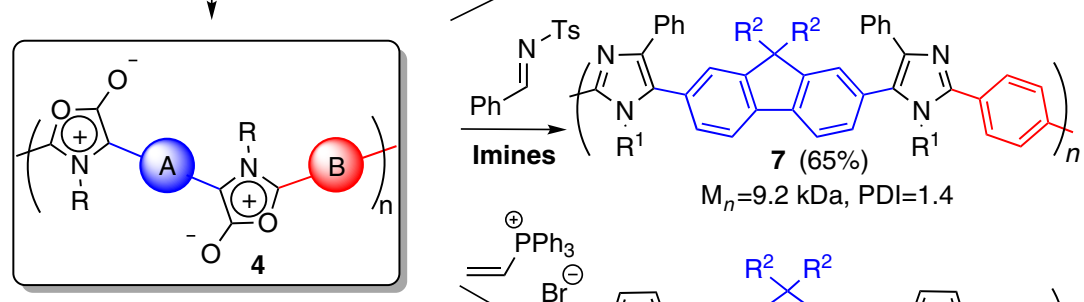

$\mathrm{M}_{n}=9.2 \mathrm{kDa}, \mathrm{PDI}=1.4$

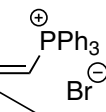

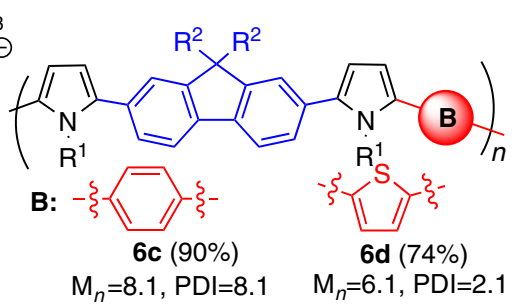

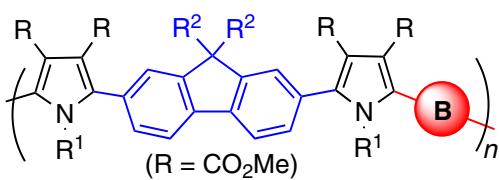

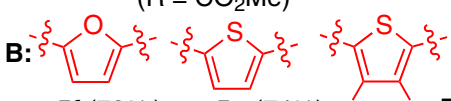

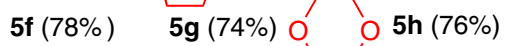

$\mathrm{M}_{n}=12.5 \mathrm{kDa} \mathrm{M}_{n}=10.8 \mathrm{kDa} \sqcup \mathrm{M}_{n}=12.8 \mathrm{kDa}$

$\mathrm{PDI}=2.6 \quad \mathrm{PDI}=2.8 \quad \mathrm{PDI}=2.6$<smiles>[R10]Cc1cc(-c2[nH]c(-c3ccc(C)cc3)c3c2C(=O)NC3=O)cc2c1C([R])([R])c1cc(-c3[nH]c(CC)c4c3C(=O)NC4=O)ccc1-2</smiles>

$\mathrm{M}_{n}=11.4 \mathrm{kDa}, \mathrm{PDI}=2.4$

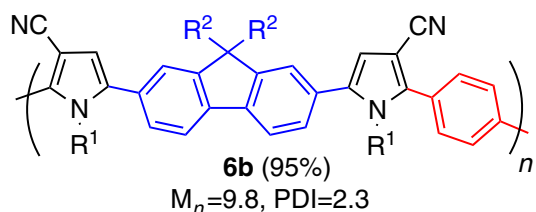

Figure 5 | Transformation of poly-Münchnones into families of conjugated polymers. Derivatization performed on poly-Münchnone samples of 8-12 kDa to ensure full solubility of $\mathbf{4 a - e}$, and allow the quantification of the cycloaddition.

$$
\begin{array}{c|c}
1 \mathbf{a}+\mathbf{2 a}+\mathrm{CO}+\mathrm{Ph}= & =\mathrm{CO}_{2} \mathrm{Me} \\
\mathrm{EtNiPr} r_{2} & 5 \% \\
\mathrm{THF} / \mathrm{MeCN}^{-} & \mathrm{Pd}\left[\mathrm{P}(\mathrm{o} \text {-tol })_{3}\right]_{2} \\
55^{\circ} \mathrm{C}, 72 \mathrm{~h} &
\end{array}
$$

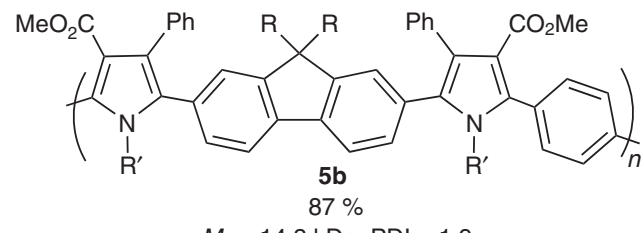

$M_{\mathrm{n}}=14.3 \mathrm{kDa}, \mathrm{PDI}=1.9$

Figure 6 | One-pot, four-component polymerization. See Supplementary Methods for experimental details.

hybrid materials derived from the following four simple substrates: vanillin, terephthaloyl chloride, a primary amine and $\mathrm{CO}$, and represent, as far as we are aware, the first use of lignin in cross-conjugated polymer formation. Considering the versatility of this reaction, it should prove relevant for the controlled assembly of a range of renewable-based conjugated polymers.

\section{Discussion}

In summary, we have described a new type of metal-catalysed multicomponent polymerization, which provides a method to convert combinations of monomers, such as diimines, diacid chlorides, CO, alkynes, alkenes and alcohols, into structurally well-defined conjugated polymers. In addition, new backbone-conjugated mesoionic polymers (4) can be prepared via
Table 2 | Properties of polymers 5-8.

\begin{tabular}{lccccc} 
Compound & $\lambda_{\max }(\mathbf{n m})$ & $\boldsymbol{\lambda}_{\mathbf{e m}} \mathbf{( n m )}$ & $\boldsymbol{\varphi}_{\mathbf{P L}}$ & $\boldsymbol{E}_{\mathbf{g}}^{\mathbf{p p t}}(\mathbf{e V})$ & $\boldsymbol{E}_{\mathbf{g}}^{\mathbf{p p t}} \mathbf{f i l m}(\mathbf{e V})$ \\
\hline $\mathbf{5 a}$ & 321 & 413 & 0.39 & 3.18 & 3.16 \\
$\mathbf{5 b}$ & 335 & 492 & 0.27 & 2.91 & 2.87 \\
$\mathbf{5 c}$ & 329 & 496 & 0.04 & 2.99 & 2.98 \\
$\mathbf{5 d}$ & 325 & 474 & 0.03 & 2.92 & 2.79 \\
$\mathbf{5 e}$ & 301 & 413 & 0.12 & 3.15 & 3.08 \\
$\mathbf{5 f}$ & 320 & 459 & 0.14 & 3.08 & 2.97 \\
$\mathbf{5 g}$ & 320 & 467 & 0.11 & 3.07 & 3.11 \\
$\mathbf{5 h}$ & 321 & 467 & 0.10 & 3.05 & 2.97 \\
$\mathbf{5 i}$ & 312 & 417 & 0.17 & 3.19 & 2.93 \\
$\mathbf{5 j}$ & 329 & 473 & 0.02 & 2.88 & 2.92 \\
$\mathbf{6 a}$ & 364 & 459 & 0.35 & 2.86 & 2.80 \\
$\mathbf{6 b}$ & 345 & 431 & 0.47 & 3.01 & 2.96 \\
$\mathbf{6 c}$ & 366 & 501 & 0.08 & 2.60 & 2.60 \\
$\mathbf{6 d}$ & 368 & 497 & 0.06 & 2.63 & 2.47 \\
$\mathbf{7}$ & 330 & 467 & 0.12 & 2.98 & 2.80 \\
$\mathbf{8}$ & 280 & - & - & 3.45 & 3.42 \\
\hline
\end{tabular}

Select physical properties of 5-8 (see Supplementary Tables 1 and 2 for further details, electrochemical studies, HOMO/LUMO energies and for properties of polymers $\mathbf{4 a - f ^ { \prime }}$ ).

this coupling, which can undergo efficient post-polymerization cycloaddition to generate families of conjugated materials. In light of the variety of dipolarophiles possible for cycloaddition, as well as diimines and bis(acid chloride)s available, this can be used to construct arrays of conjugated materials, yet without the typical need to preassemble each new conjugated unit, and with the efficiency often desired in polymer synthesis. This multicomponent catalytic polymerization approach could prove equally applicable for the controlled assembly of a range of new materials 


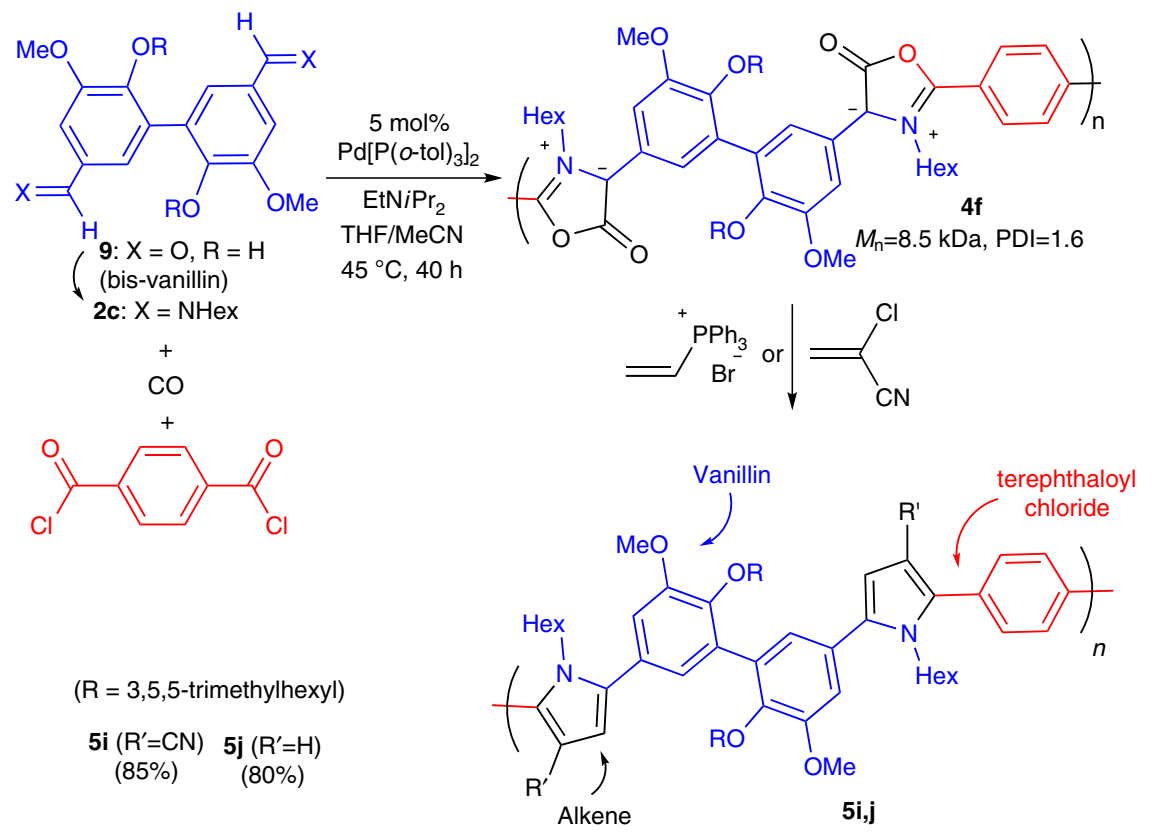

Figure 7 | Conjugated polymers from vanillin. Multicomponent synthesis of polymer $\mathbf{4} \mathbf{f}$ and its derivatization to $\mathbf{5 i}$ and $\mathbf{5 j}$.

from established monomers and/or other inexpensive building blocks. Experiments directed towards the latter are currently underway.

\section{Methods}

General procedure for the synthesis of poly-Münchnones and polyheterocycles. To diacid chloride $\mathbf{1}(0.1 \mathrm{mmol})$ and diimine $2(0.100 \mathrm{mmol})$ in THF $(0.6 \mathrm{ml})$ in a 5 -ml vial under $\mathrm{N}_{2}$ was added $N, N$-diisopropylethylamine $(51.7 \mathrm{mg}, 70.0 \mu \mathrm{l}$, $0.400 \mathrm{mmol})$, and $\mathrm{Pd}\left[\mathrm{P}(o-\text { tol })_{3}\right]_{2}(7.2 \mathrm{mg}, 0.010 \mathrm{mmol})$ in $1.3 \mathrm{ml} \mathrm{THF}(1.3 \mathrm{ml}) / \mathrm{MeCN}$ $(0.6 \mathrm{ml})$. The vial was placed in a $40-\mathrm{ml}$ Parr steel autoclave, charged with CO (20 bar) and heated to $45^{\circ} \mathrm{C}$. (For the imine endcapped poly-Münchnone, p-tolyl $(\mathrm{H}) \mathrm{C}=\mathrm{NC}_{16} \mathrm{H}_{37}$ was added; see Supplementary Methods for details.) The $\mathrm{CO}$ was evacuated, the vessel was brought into a glovebox and the appropriate dipolarophile in $1.5 \mathrm{ml}$ THF was added. The reaction was stirred at room temperature or $50^{\circ} \mathrm{C}$ for $16 \mathrm{~h}, 0.2 \mathrm{ml}$ water was added and the polymer product was extracted with $o$-dichlorobenzene using a Soxhlet extractor. The solvent was removed in vacuo, and the residue was dissolved with a minimum amount of hot chloroform $(\sim 1 \mathrm{ml})$ and added dropwise into methanol $(\sim 20 \mathrm{ml})$ to precipitate the polymer. The suspension was centrifuged and the methanol layer was decanted. The polymer was washed with methanol $(3 \times 2 \mathrm{ml})$ before drying in vacuo at $50^{\circ} \mathrm{C}$. See Supplementary Methods for further information. For NMR analysis, ultraviolet/ visible, fluorescence and cyclic voltammetry of the molecules in this article, see Supplementary Figs 1-7.

\section{References}

1. Audebert, P. in Electropolymerization: Concept, Materials and Applications. (eds Cosnier, S. \& Karyakin, A.) 77-91 (Wiley-VCH, 2010).

2. Fichou, D. (ed.) Handbook of Oligo- and Polythiophenes (Wiley-VCH, 1999).

3. Osaka, I. \& McCullough, R. D. in Design and Synthesis of Conjugated Polymers. (eds Leclerc, M. \& Morin, J.-F.) 91-145 (Wiley-VCH, 2010).

4. Zhou, H., Yang, L. \& You, W. rational design of high performance conjugated polymers for organic solar cells. Macromolecules 45, 607-632 (2012).

5. Coughlin, J. E., Henson, Z. B., Welch, G. C. \& Bazan, G. C. Design and synthesis of molecular donors for solution-processed high-efficiency organic solar cells. Acc. Chem. Res. 47, 257-270 (2014).

6. Morin, J.-F., Leclerc, M., Adès, D. \& Siove, A. Polycarbazoles: 25 years of progress. Macromol. Rapid Commun. 26, 761-778 (2005).

7. Facchetti, A. $\pi$-Conjugated polymers for organic electronics and photovoltaic cell applications. Chem. Mater. 23, 733-758 (2010).

8. Heeger, A. J. 25th Anniversary Article: bulk heterojunction solar cells: understanding the mechanism of operation. Adv. Mater. 26, 10-28 (2014).

9. Grimsdale, A. C., Leok Chan, K., Martin, R. E., Jokisz, P. G. \& Holmes, A. B. Synthesis of light-emitting conjugated polymers for applications in electroluminescent devices. Chem. Rev. 109, 897-1091 (2009).
10. Ates, M. A review study of (bio)sensor systems based on conducting polymers. Mat. Sci. Eng. C 33, 1853-1859 (2013).

11. Babudri, F., Farinola, G. M. \& Naso, F. Synthesis of conjugated oligomers and polymers: the organometallic way. J. Mater. Chem. 14, 11-34 (2004).

12. Okamoto, K. \& Luscombe, C. K. Controlled polymerizations for the synthesis of semiconducting conjugated polymers. Polym. Chem. 2, 2424-2434 (2011).

13. Burke, D. J. \& Lipomi, D. J. Green chemistry for organic solar cells. Energy Environ. Sci. 6, 2053-2066 (2013).

14. Okamoto, K., Zhang, J., Housekeeper, J. B., Marder, S. R. \& Luscombe, C. K. $\mathrm{C}-\mathrm{H}$ arylation reaction: atom efficient and greener syntheses of $\pi$-conjugated small molecules and macromolecules for organic electronic materials. Macromolecules 46, 8059-8078 (2013).

15. Mercier, L. G. \& Leclerc, M. Direct (hetero)arylation: a new tool for polymer chemists. Acc. Chem. Res. 46, 1597-1605 (2013).

16. Jieping Zhu, H. B. (ed.) Multicomponent Reactions (Wiley-VCH, 2005).

17. Dömling, A. \& Ugi, I. Multicomponent reactions with isocyanides. Angew. Chem. Int. Ed. 39, 3168-3210 (2000).

18. D'Souza, D. M. \& Muller, T. J. J. Multi-component syntheses of heterocycles by transition-metal catalysis. Chem. Soc. Rev. 36, 1095-1108 (2007).

19. Balme, G., Bossharth, E. \& Monteiro, N. Pd-assisted multicomponent synthesis of heterocycles. Eur. J. Org. Chem 2003, 4101-4111 (2003).

20. Montgomery, J. Nickel-catalyzed reductive cyclizations and couplings. Angew. Chem. Int. Ed. 43, 3890-3908 (2004).

21. Kakuchi, R. Multicomponent reactions in polymer synthesis. Angew. Chem. Int Ed. 53, 46-48 (2014).

22. Choi, C.-K., Tomita, I. \& Endo, T. Synthesis of novel $\pi$-conjugated polymer having an enyne unit by palladium-catalyzed three-component coupling polymerization and subsequent retro-diels - alder reaction. Macromolecules 33, 1487-1488 (2000).

23. Nakagawa, K. \& Tomita, I. Synthesis of poly(p-phenylene-vinylene) with chiral higher-order structure from simple monomers by three-component coupling polymerization. Macromolecules 40, 9212-9216 (2007).

24. Takenoya, K. \& Yokozawa, T. Simultaneous construction of polymer backbone and side chains by three-component polycondensation. synthesis of polyethers with cyano side chains from dialdehydes, alkylene bis(trimethylsilyl) ethers, and cyanotrimethylsilane. Macromolecules 31, 2906-2910 (1998).

25. Chan, C. Y. K. et al. Construction of functional macromolecules with welldefined structures by indium-catalyzed three-component polycoupling of alkynes, aldehydes, and amines. Macromolecules 46, 3246-3256 (2013).

26. Lee, I.-H., Kim, H. \& Choi, T.-L. Cu-catalyzed multicomponent polymerization to synthesize a library of poly(n-sulfonylamidines). J. Am. Chem. Soc. 135, 3760-3763 (2013).

27. Kreye, O., Kugele, D., Faust, L. \& Meier, M. A. Divergent dendrimer synthesis via the Passerini three-component reaction and olefin cross-metathesis. Macromol. Rapid. Commun. 35, 317-322 (2014). 
28. Dhawan, R., Dghaym, R. D. \& Arndtsen, B. A. The development of a catalytic synthesis of münchnones: a simple four-component coupling approach to $\alpha$-amino acid derivatives. J. Am. Chem. Soc. 125, 1474-1475 (2003).

29. Lu, Y. \& Arndtsen, B. A. Palladium catalyzed synthesis of münchnones from $\alpha$-amidoethers: a mild route to pyrroles. Angew. Chem. Int. Ed. 47, 5430-5433 (2008).

30. Siamaki, A. R., Sakalauskas, M. \& Arndtsen, B. A. A palladium-catalyzed multicomponent coupling approach to pi-conjugated oligomers: assembling imidazole-based materials from imines and acyl chlorides. Angew. Chem. Int. Ed. 50, 6552-6556 (2011).

31. Manecke, G. \& Klawitter, J. Zur synthese von makromolekülen durch 1,3-dipolare cycloaddition aus mesoionischen oxazolonen, 3. Die Makromol. Chem. 175, 3383-3399 (1974).

32. Gingrich, H. L. \& Baum, J. S. in Chemistry of Heterocyclic Compounds: Oxazoles. (ed. Turchi, I. J.) 45, 731-961 (John Wiley \& Sons, Inc., 2008).

33. Biniek, L., Schroeder, B. C., Nielsen, C. B. \& McCulloch, I. Recent advances in high mobility donor-acceptor semiconducting polymers. J. Mater. Chem. 22, 14803-14813 (2012).

34. Bozell, J. J. \& Petersen, G. R. Technology development for the production of biobased products from biorefinery carbohydrates-the US Department of Energy's "Top 10" revisited. Green Chem. 12, 539-554 (2010).

35. Lucht, B. L., Buretea, M. A. \& Tilley, T. D. A zirconocene-coupling route to substituted poly(p-phenylenedienylene)s: band gap tuning via conformational control. J. Am. Chem. Soc. 120, 4354-4365 (1998).

36. He, G. et al. The marriage of metallacycle transfer chemistry with suzukimiyaura cross-coupling to give main group element-containing conjugated polymers. J. Am. Chem. Soc. 135, 5360-5363 (2013).

37. For non-conjugated examples to post polymerization derivatizationLeibfarth, F. A. et al. A facile route to ketene-functionalized polymers for general materials applications. Nat. Chem. 2, 207-212 (2010).

38. Wang, L.-X., Li, X.-G. \& Yang, Y.-L. Preparation, properties and applications of polypyrroles. React. Funct. Polym. 47, 125-139 (2001).

39. Tamilavan, V. et al. Synthesis and photovoltaic properties of donor-acceptor polymers incorporating a structurally-novel pyrrole-based imide-functionalized electron acceptor moiety. Polymer 54, 6125-6132 (2013).

40. Nishinaga, T. et al. Synthesis and structural, electronic, optical and FET properties of thiophene-pyrrole mixed hexamers end-capped with phenyl and pentafluorophenyl groups. J. Mater. Chem. 21, 14959-14966 (2011).
41. Zakzeski, J., Bruijnincx, P. C. A., Jongerius, A. L. \& Weckhuysen, B. M. The catalytic valorization of lignin for the production of renewable chemicals. Chem. Rev. 110, 3552-3599 (2010).

\section{Acknowledgements}

We thank NSERC, CFI and the FQRNT supported Centre for Green Chemistry and Catalysis, and the NSERC Biomaterials and Chemicals Research Network (Lignoworks) for funding this work. D.C.L. and E.N.K. thank NSERC for a PDF and a USRA, respectively. We thank Professor Perepichka for access to his cyclic voltametry, ultraviolet and fluorescence instruments. We thank CSACS for access to the GPC. We thank Julia Schneider for her support in the CV measurements.

\section{Author contributions}

B.A.A. conceived and directed the project. D.C.L., L.V.K. and Z.-Y.H. carried out the experiments and characterized the polymers. D.C.L., L.V.K. and Z.-Y.H. contributed equally to this work. A.R.S., A.G. and E.N.K. performed preliminary experiments.

\section{Additional information}

Supplementary Information accompanies this paper at http://www.nature.com/ naturecommunications

Competing financial interests: The authors declare no competing financial interests.

Reprints and permission information is available online at http://npg.nature.com/ reprintsandpermissions/

How to cite this article: Leitch, D. C. et al. A palladium-catalysed multicomponent coupling approach to conjugated poly(1,3-dipoles) and polyheterocycles. Nat. Commun. 6:7411 doi: 10.1038/ncomms8411 (2015).

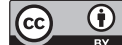

This work is licensed under a Creative Commons Attribution 4.0 International License. The images or other third party material in this article are included in the article's Creative Commons license, unless indicated otherwise in the credit line; if the material is not included under the Creative Commons license, users will need to obtain permission from the license holder to reproduce the material. To view a copy of this license, visit http://creativecommons.org/licenses/by/4.0/ 